\title{
O ATO FOTOGRÁFICO NA EDUCAÇÃO AMBIENTAL: UMA EXPERIÊNCIA NA REDE PÚBLICA DE EDUCAÇÃO INFANTIL DE JOINVILLE (SC)
}

\author{
Felipe Nobrega Ferreira ${ }^{1}$; Rachel Hidalgo²; José Vicente de Freitas ${ }^{3}$
}

\section{RESUMO}

O presente artigo apresenta uma narrativa textual-fotográfica elaborada durante a produção do documentário 4 1, 2, 3 Brincando - Reinventando os espaços escolares, o qual está vinculado a um programa de Educação Ambiental (EA) da rede pública de Educação Infantil de Joinville-SC, e possui a orientação e acompanhamento do grupo de pesquisa Ribombo (FURG/PPGEA). O material textual e fotográfico será problematizado pelo viés de uma abordagem qualitativa, valendo-se do olhar do fotógrafo enquanto elo subjetivo de uma construção narrativa baseada no encontro que se dá entre os sujeitos mediados por uma câmera fotográfica. Com isso, o intuito é realizar uma primeira reflexão crítica acerca das possibilidades de intervenções socioambientais a partir do suporte imagético em espaços de educação formal.

Palavras-chave: Educação Ambiental. Fotografia. Espaços Educadores Sustentáveis.

\section{THE PHOTOGRAPHIC ACT IN ENVIRONMENTAL EDUCATION: AN EXPERIENCE IN THE REDE PÚBLICA DE EDUCAÇÃO INFANTIL DE JOINVILLE (SC)}

\begin{abstract}
This article presents a textual-photographic narrative elaborated during the production of the documentary ${ }^{5} 1,2,3$ Brincando - Reinventando espaços escolares, which is linked to an Environmental Education (EA) program of the public network of Early Childhood Education of Joinville-SC, and has the guidance and follow-up of the Ribombo research group (FURG / PPGEA). The textual and photographic material will be problematized by the bias of a qualitative approach, taking advantage of the photographer's gaze as a subjective link of a narrative construction based on the encounter that occurs
\end{abstract}

1 Mestre. Doutorando em Educação Ambiental. Universidade Federal do Rio Grande PPGEA/FURG. E-mail: ffnobregaea@gmail.com.

2 Mestranda em Educação Ambiental. Universidade Federal do Rio Grande - PPGEA/FURG. E-mail: rachelhidalgo@ribombo.com.

3 Pós-Doc em Ciências Ambientais. Universidade Federal do Rio Grande - PPGEA/FURG. Email: josevicentedefreitas@ribombo.com.

${ }^{4} \mathrm{O}$ presente trabalho foi realizado com apoio da Coordenação de Aperfeiçoamento de Pessoal Nível Superior - Brasil (CAPES) - Código de Financiamento 001.

${ }^{5}$ This study was financed in part by the Coordenação de Aperfeiçoamento de Pessoal de Nível Superior - Brasil (CAPES) - Finance Code 001. 
between the subjects from the mediation of a photographic camera. With this, the intention is to carry out a first critical reflection on the possibilities of socioenvironmental interventions from the imaginary support in spaces of formal education.

Keywords: Environmental Education. Photography. Spaces for Sustainable Education.

\section{Primeiras lentes}

As lentes de uma objetiva percorrem por entre muros e paredes, encontram salas de aula, alcançam pátios, enfrentam o gris de um dia nublado ou o sol a pino do meio da tarde. Elas captam imagens, mas logo surge o som. O sinal que interpõe os horários, um ruído que se transforma na nitidez sonora de vários passos aos quais ainda não é possível identificar do que se trata para além das várias rápidas batidas no solo intercaladas por vozes indistinguíveis. Agora, elas captam a chegada das crianças neste cenário. Acontece 0 encontro!

E aqui o encontro que descrevemos se dá para além daquele proporcionado por uma câmera, ele ocorre no âmbito daquilo que está por trás dela, da experiência humana que é colocar-se na posição dessa relação entre quem fotografa e quem é fotografado. Assim, se desfaz o caráter "objetivo", valendo-se das tantas metáforas que a fotografia proporciona, e entra nesse enquadramento uma subjetividade a qual não é mais possível deixar de lado. Afinal, estamos falando de encontro, para ser ainda mais claro, do encontro de sujeitos mediados por uma câmera fotográfica.

Assim, as lentes mediam as escolhas de ambas as partes, visto que, ser o fotógrafo, e saber-se fotografado, impõe uma dinâmica experiencial singular. A preparação, a escolha do que registrar, o cenário, entre outros elementos, faz parte do conjunto de intencionalidades do fotógrafo, enquanto a surpresa, a performance, a opção em mostrar-se ou esconder-se, surge de quem está do outro lado e participa dessa circularidade da fotografia sendo construída.

Sendo assim, o presente trabalho visa apresentar o primeiro conjunto de intervenções realizadas no contexto do documentário 1, 2, 3 Brincando Reinventando Espaços Escolares realizado pelo grupo de pesquisa 
multidisciplinar em Educação Ambiental Ribombo ${ }^{6}$, da Universidade Federal do Rio Grande (FURG). O documentário é fruto de uma cooperação com a Secretaria Municipal de Educação de Joinville- SC, com vista ao adensamento desta proposta no âmbito do ensino formal infantil (Centros de Educação Infantil - CEl's) e a sua extensão ao ensino fundamental daquela rede de educação.

Nesse texto, em particular, o intuito é problematizar o olhar fotográfico que acompanha a produção do referido documentário no âmbito desse programa. Tal material será distribuído junto às redes públicas municipais e estaduais de ensino do país e possui como fundamento práticas socioambientais assentadas no campo da Educação Ambiental, com ênfase na perspectiva dos espaços educadores sustentáveis.

A produção fotográfica, logo, traz um repertório de sentidos ambientais que estão postos na tessitura desse material, e que ganham aqui a primeira reflexão crítica. Com isso, a intenção é não só publicizar o que está em andamento, tornando o processo de criação fotográfica parte das contribuições à $E A$, mas também trazer à tona possibilidades de intervenções socioambientais a partir do suporte da fotografia e sua potência para o encontro entre os sujeitos envolvidos nessa trama que se tece pela subjetividade que envolve cada registro.

\section{Ajustando o foco}

Como interpretar uma fotografia junto à EA? De que forma buscar aportes para compreender o que está exposto e o que é velado em um registro imagético? Ainda, o que está por trás da imagem e funde-se às intencionalidades de quem fotografa?

Tais questões orientam a busca de metodologias caracterizadas por uma abordagem qualitativa, a qual reconhece elementos que Nibaldo Triviños aponta de três formas: 1) a tendência de natureza desreificadora dos fenômenos, do conhecimento e do ser humano, e a rejeição da neutralidade do saber científico; 2) a postura de uma 'pesquisa participante' visando um

\footnotetext{
${ }^{6}$ O Grupo de Pesquisa Ribombo - Estudos em Educação e Gestão Ambiental, Mudanças Climáticas e Objetivos do Desenvolvimento Sustentável em áreas litorâneas é composto por pesquisadores que possuem formação em áreas (Jornalismo, História, Oceanografia, Direito, Gestão Ambiental) e atuam, desde 2017, no aprofundamento teórico e propositivo de questões que conectam EA e zonas costeiras.
} 
enfoque dialético, com objetivo de transformar a realidade que se estuda; 3) os obstáculos que surgem da generalização, o que exige atenção redobrada para não recriar uma linearidade científica em que as respostas já estão dadas à priori visto o caráter "relativamente parcial" (TRIVIÑOS, 1987, p. 125-126).

Indo ao encontro das palavras de Triviños é possível dizer que, na perspectiva qualitativa, o ambiente é uma fonte direta de dados e o pesquisador interessa-se, também, pelo processo, sendo esse elemento central para discussão do problema que se impõe à análise (CRESWEL, 2007, p. 186). Nesse escopo, pensar uma abordagem qualitativa a partir do suporte da fotografia compreende, então, ter em mente que toda e qualquer interpretação não se inicia no ato revelado, na pós-produção quando a imagem está dada, objetivada no tempo, mas começa no olhar sensível de quem fotografa e o que isso pode revelar sobre o que foi escolhido.

As palavras de Philippe Dubois podem colaborar para essa compreensão quando argumenta sobre o que chama de "atitudes fotográficas":

a imagem fotográfica não é um espelho do neutro, mas um instrumento de transposição, de análise, de interpretação e até de transformação do real, como a língua, por exemplo, e assim, também, culturalmente modificada (DUBOIS, 1993, p. 26).

Nesse percurso da produção de uma imagem, o ato fotográfico possui primeiro uma potência subjetiva inerente. Como em um espelhamento entre olhares, a construção de sentidos se dá no processo, transcende a intencionalidade individual do fotógrafo quando ocorre o encontro com 0 fotografado. Da mesma forma, adquire potência transformadora ao possibilitar, através desse encontro, construir outro olhar sobre o ambiente que os cerca. Daí a importância em tornar a fotografia um elemento a ser problematizado e interpretado junto ao campo da Educação Ambiental, encarando esse suporte não como um dado acabado, mas sim como um registro sensível que é capaz de projetar ações educativas nos mais variados contextos.

Um exemplo que serve como inspiração metodológica ao presente artigo é o trabalho do educador ambiental Leandro Belinaso Guimarães. Em uma publicação vinculada ao grupo de trabalho Tecendo, do qual Guimarães é um dos coordenadores, fica claro que o intuito com 0 uso do aporte fotográfico/imagético é a construção do que o pesquisador concebe como 
"ecologias inventivas", a qual visa proporcionar um "desfazer propostas prontas" (PREVE, 2015, p. 9) - como aponta o prefácio de Ana Maria Preve junto a uma das publicações do referido grupo.

Quando Guimarães, em trabalho escrito com Preve, compreende que "(...) nos modos como lemos uma imagem, há um pouco daquilo que pensamos ser" (GUIMARÃES; PREVE, 2013, p. 49), torna-se possível perceber esse circuito que percorre o fazer fotográfico, já que dota o fotógrafo de uma subjetividade que não se encerra no ato de um clique, mas sim se estende no tempo e nas alternativas de uso desse material, dando vasão a uma afirmação que os autores reivindicam quando anunciam que "da paisagem que vemos, já não podemos nos retirar" (LEAL apud GUIMARÃES; PREVE, 2013, p. 49). Assim, para eles, a importância está em deslocar-se dos modos que nos acostumamos a ver, o que faz do uso da produção de imagens/fotografias o fio condutor dessa possibilidade.

Trabalho que emoldura a postura crítica do referido autor pode ser observado em $A$ (in)sustentabilidade da imagem (2015), quando analisa, através de ensaios, imagens jornalísticas relativas à sustentabilidade. Em seu texto, esse universo é retratado elaborando exatamente esse movimento que vai do olhar subjetivo entrecruzado entre quem produz e quem visualiza a produção fotográfica - movimento que Guimarães complexifica quando trata, também, da decomposição da imagem.

Ao trazer para o nosso artigo algumas das contribuições de Guimarães, especificamente no exercício que realiza em apresentar o mundo-imagem como um texto a ser lido junto aos fundamentos da EA, podemos encontrar algumas vias abertas à interpretação desse tipo de suporte, ao mesmo tempo em que se desbrava outras. E assim, ao apresentar a experiência do ato fotográfico dentro do projeto 1, 2, 3 Brincando, a possibilidade de contribuir a esse tipo de debate torna-se efetiva.

No âmbito das metodologias qualitativas trazemos a pesquisa participante enquanto horizonte, visto que ela "pressupõe, necessariamente, a participação ativa do pesquisador no contexto, grupo ou cultura que estuda/investiga em articulação com os sujeitos que estão envolvidos no processo de investigação" (MARTINS, 2015, p. 39-40). Nesse ponto lembramos das palavras de Larrosa (2002) quando diz que a experiências é o 
que nos acontece; o passo seguinte do nosso trabalho é o relato de quem fez a fotografia, nesta ocasião, da fotógrafa do grupo de pesquisa Ribombo.

Serão apresentadas cinco fotografias ${ }^{7}$ as quais surgem devidamente creditadas e referenciam as instituições em que foram produzidas. Visando tecer uma narrativa específica, pedimos licença para dispor cada uma delas em uma página, acompanhadas de uma narrativa elaborada através do diário de campo da fotógrafa, contribuindo ao projeto conceitual que as atravessa, e que, nesse caso, compreende uma construção corporal que se conecta a atividade, e ao registro do encontro.

Assim, o presente relato traz texto, fotografia e som. Texto na medida em que, nesse momento, ele é elaborado pela fotógrafa; a fotografia está como a mediação da inflexão proposta; e som quando a música Grama Verde ${ }^{8}$ do cantautor Vitor Ramil visa encontrar o dia real dentro das cenas ideais que compõe esse universo interpretativo que apresentamos a seguir.

\section{Corpo interposto}

Quando cheguei à Joinville para conhecer o primeiro CEI, já sabia que éramos ansiosamente aguardados/as: o cheiro de café fresco rondava o lugar, além de uma mesa farta de pães e inúmeros docinhos catarinenses que compunham as boas vindas da rede pública de Educação Infantil. Já tendo recebido o briefing para o trabalho, isto é, as informações que precisava captar na imagem, formava uma ideia dos lugares e/ou pessoas para os quais iria apontar minhas lentes. Porém, viver a experiência, no meu caso, por uma semana submersa naquele universo, fez uma notória diferença em minhas fotos, que fui percebendo nas imagens que escolhia produzir conforme os dias passavam: primeiro dentro do espaço escolar, mas não em uma sala de aula, depois totalmente "fora" deste espaço - adianto que este último, após as visitas, ganhou outro sentido para mim.

Acredito que uma estratégia dos/as responsáveis pela rede tenha sido me levar primeiramente aos CEl's que contavam com mais metros quadrados,

\footnotetext{
7 Todos os direitos de imagens e autorizações de uso estão abarcadas junto à produção do documentário em questão.

8 Letra e melodia foram compostas pelo próprio Vitor Ramil, sendo que a canção faz parte do álbum "À beça" (1995).
} 
afinal, a primeira impressão é importante e, realmente, a conquista de locais como bosques, lagos, hortas e outros para a rede de educação é algo relevante de ser exibido com orgulho. Por outro lado, não foi nenhuma surpresa que cenários fossem naturalmente orquestrados assim que eu adentrasse aos lugares.

Isso porque, sem o auxílio dos/as profissionais, eu teria dificuldade de captar as imagens das crianças em horário de aula e intervir na rotina de todos/as, além disso, deixar que os/as estudantes saíssem das salas nos horários aleatórios em que eu chegava, para interagirem nos ambientes preparados, era uma forma de mostrar o potencial de seus trabalhos para que eu pudesse registrar. Como era o combinado. E, assim, iniciei meu intento em dar uma imagem ao projeto.

Como de praxe, a maioria das fotos, por mais que tenham sido realizadas de acordo com técnicas específicas, trataram de mostrar uma ideia geral, ideal: crianças em seus espaços - pensados e realizados, junto aos/às educadores/as - com materiais reciclados e conjugados ao ambiente natural. Nomeio "ambiente natural" somente para facilitar o entendimento, pois tenho como referência o meio ambiente em seu sentido amplo $^{9}$, como vou narrar mais adiante, ao menos em uma concepção teórica.

E compondo um material com grande número de gigabytes, produzi aquilo que me foi solicitado, fugindo do mero registro documental, até mesmo porque é notável que o trabalho que tem se desenvolvido na região nos provoca a produzir muito mais no que diz respeito às sensibilidades.

No entanto, algumas dessas fotografias - não necessariamente aquelas que tornam visível a ementa do projeto na imagem, e também, não necessariamente aquelas que considero mais satisfatórias tecnicamente/artisticamente - me tocaram de maneira diferente. Estas acionaram outros endereçamentos em meu repertório de educadora ambiental que, naquela ocasião, estava com uma câmera na mão.

Essas fotos a que me refiro me provocaram a pensar em nossa corporeidade $^{10}$. Fez se desvelar em minha mente que criamos linhas invisíveis que nos cercam e impedem de ocupar certos lugares demarcados para cada

\footnotetext{
9 Vide REIGOTA (2001, p. 21).
}

10 Vide CHAVEIRO (2012). 
dimensão da nossa vida: nesta área, se faz isso; noutra, aquilo. Não se pode transpor tais espaços, afinal, existe essa linha que os divide. Fazemos isso há tanto tempo que se tornou algo condicionado.

Prontamente me deslocou para o conceito de socioambiental, superando a dicotomia entre natureza e sociedade (CARVALHO, 2008). E como perdemos em não, de fato, levar esse sentido para a nossa prática social na grande maioria das vezes. Perdemos, literalmente, espaço em nosso próprio habitat. Tenho uma ideia de que, para pesquisadores/as do campo do Ensino Formal, esse entendimento seja ainda mais nítido, por conta de sua posição, no front da questão. Em meu turno, estudante de Fundamentos da Educação Ambiental, o enxergo totalmente enraizado em um paradigma definidor das nossas relações.

Depois da experiência, percebi o delineamento de um estado de (1) estética, (2) limpeza, (3) perfeição, (4) solidão e (5) espaço, os quais tento imprimir a seguir. Para amplificar tal percepção, convoco também, além das imagens, a letra da música Grama Verde (RAMIL, 2000), que me parece bem costurada às ideias que rondavam a minha cabeça durante esse processo de produção: o momento de fotografar; selecionar e editar as imagens; mostrar aos/às colegas do grupo de pesquisa e ouvir seus comentários e impressões; revisar o repertório do campo da Educação Ambiental; e, por fim, o momento da escrita, que empresta ainda mais um elemento à esta composição de tantas mãos.

Foto 1: CEI Raio de Sol, jun/2018, Joinville-SC

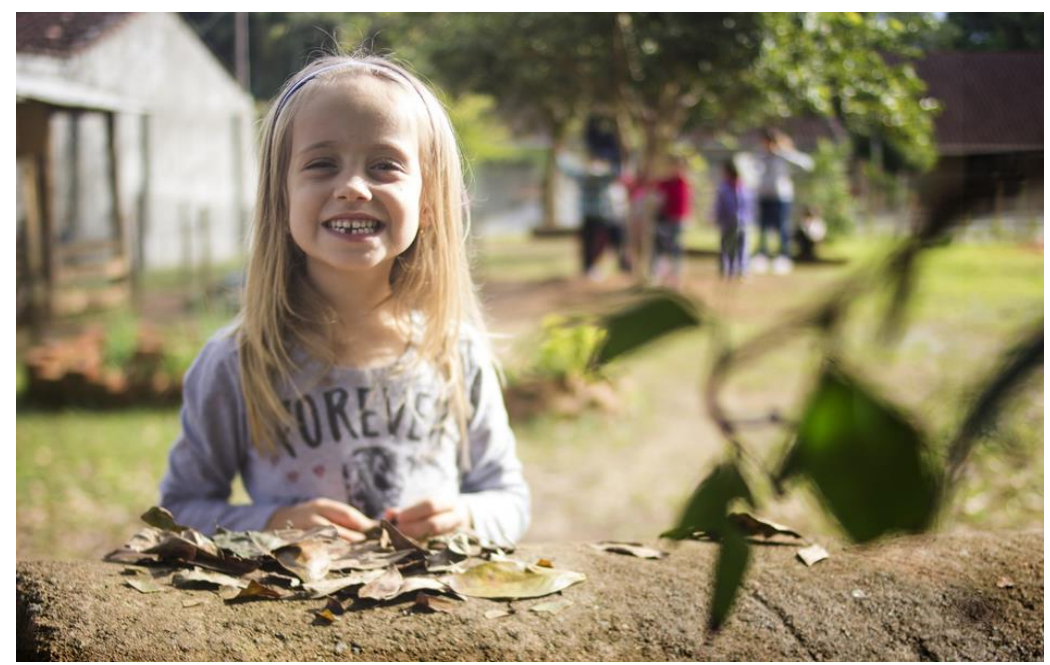

Fonte: Fotografia Rachel Munhoz 


\section{Tronco de uma ideia ideal}

Na luz do dia não passei a tinta Que luz tão clara só com sol se pinta Que seja o dia real Se eu quero a cena ideal (V. Ramil)

Essa foi uma das primeiras imagens que fiz. E me pego recordando que efeitos eu imaginei produzir, no sentido de inscrever uma noção de espaço sustentável, endereçando-a para um trabalho do campo da educação ambiental. Obviamente, fiz questão de registrar a estudante enquanto brincava com materiais "da natureza", mostrando sua presença no bosque localizado no terreno do próprio CEl, posando espontaneamente, com outras crianças brincando ao fundo. Enquadrei tudo que eu acreditei ser ideal para referenciar a minha ideia: o tronco superior da minha protagonista, que olha diretamente para a lente, à esquerda do quadro, quase descolada do fundo e próxima de quem "vê" a foto. Quase como um cumprimento de boas vindas ao seu universo, o universo escolar que eu produzi para ela neste quadro. Tal construção discursiva, em imagem, contou com a luz do sol para dar o tom dourado à fotografia, remetendo à felicidade, vida saudável, vida feliz, entre outros adjetivos que compõem uma determinada noção de beleza. Acredito que minha intencionalidade estava na mensagem circunscrita em uma estética da felicidade: "as crianças são mais felizes estudando em ambientes assim".

Foto 2: CEI Prof ${ }^{a}$ Herondina da Silva Vieira, jun/2018, Joinville-SC

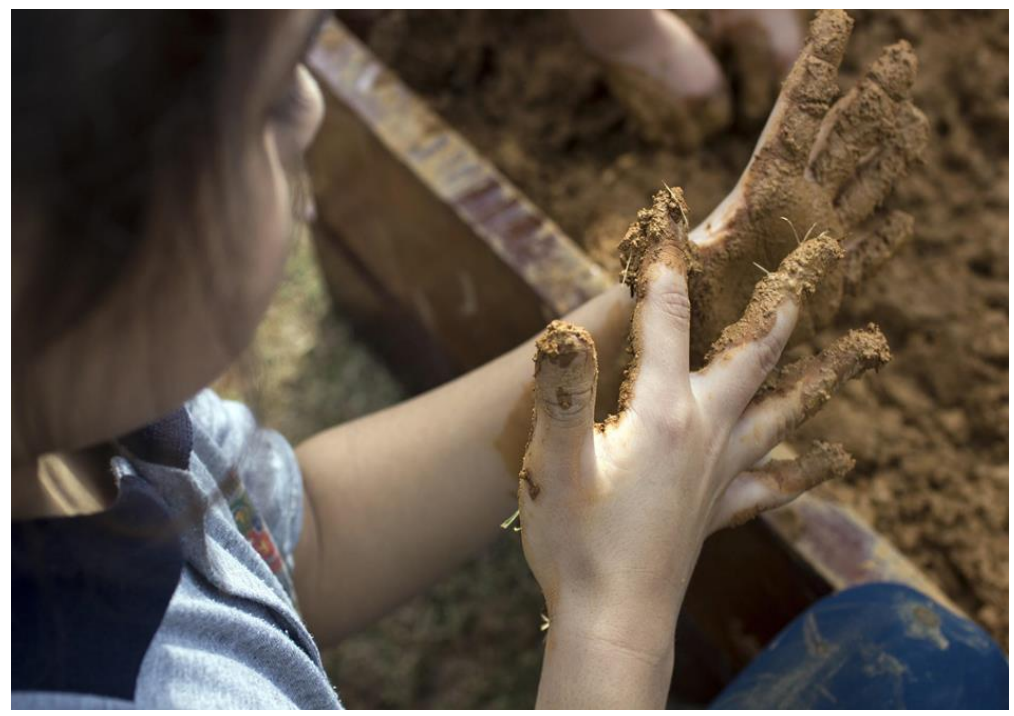

Fonte: Fotografia Rachel Munhoz. 


\section{Mão na massa viva}

Olhando a cena é que eu me sinto vivo

A segunda foto enuncia o famoso "mão na massa". Uma criança com as mãos sujas após brincar na caixa de lama. Ao fundo, do lado superior direito, vemos desfocadas outras mãos infantis no momento de seu contato com a terra. A luz natural incidindo nas mãos da protagonista da foto para chamar a atenção do/a espectador/a. Essa imagem foi produzida a partir da ideia de que se sujar é um ato de liberdade, contradizendo o que normalmente, no sentido de que acontece mais vezes, se faz no ambiente escolar. A sujeira como uma ação libertária no universo infantil já nos é dado e continua ocupando um lugar indesejado na prática. A sujeira, da mesma forma que o barulho - uma sujeira audível. Voltando para a imagem acima, tentei denotar um sentido de emancipação de todas essas amarras, como se essa criança estivesse "cavando" o seu direito de brincar livremente, se sujar, aprender com o que se sente, se sentir vivo/a, enfim.

Foto 3: CEI Antonio Bruhmuller, jun/2018, Joinville- SC

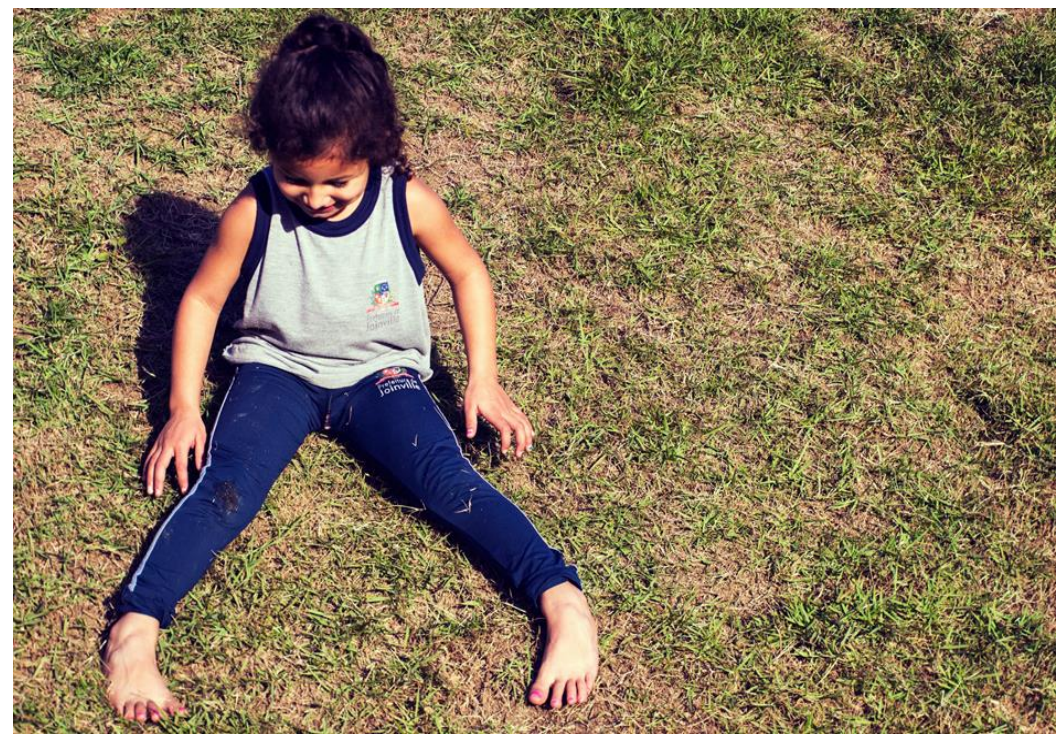

Fonte: Fotografia Rachel Munhoz.

\section{Pé na grama}

Pintei a grama pro teu passo é claro Teu passo forte e falso e vivo e raro (V. Ramil) 
Quando abri essa imagem em meu computador, confesso, quase a descartei. Isso porque o verde e marrom, apesar de geralmente serem coreschave do tema meio ambiente, não me parecem formar uma porção tão bonita para preencher quase todo o quadro. A grama está desfalcada, provavelmente porque as pessoas pisaram sem cuidado, crianças brincaram e jogaram bola, deixando buracos de terra à mostra. Além disso, não consegui captar uma cor avivada, nítida, nem marrom, nem verde, resultando em um tom um tanto amarelado. Por outro lado, senti que essa grama desalinhada, ironicamente, mostra, exatamente, que foi pisada, vivida, experienciada. Os pés da garota na foto, em evidência pelo posicionamento de suas pernas, nos dá essa sensação de não ter medo do contato. E este é o endereçamento que vejo para a mensagem desta imagem. Tal compreensão convoca ao paradigma derivado do antropocentrismo: o perfeccionismo. "A busca obstinada pela perfeição ou pela eliminação daquilo que se julga ser 'naturalmente' defeituoso e, que, portanto, precisa ser aprimorado" (LAYRARGUES, 2012, p.82). Certamente a grama não estaria nessas condições se as pessoas não vivessem nela, porém, ela só estaria em perfeito estado se nada vivesse sob ela para atrapalhar seu tom homogêneo de um verde perfeito. Aqui, como o trecho da música de Ramil, ele nos dá sinais do passo forte e falso e vivo e raro.

Foto 4: CEI Alegria de Viver, jun/2018, Joinville - SC

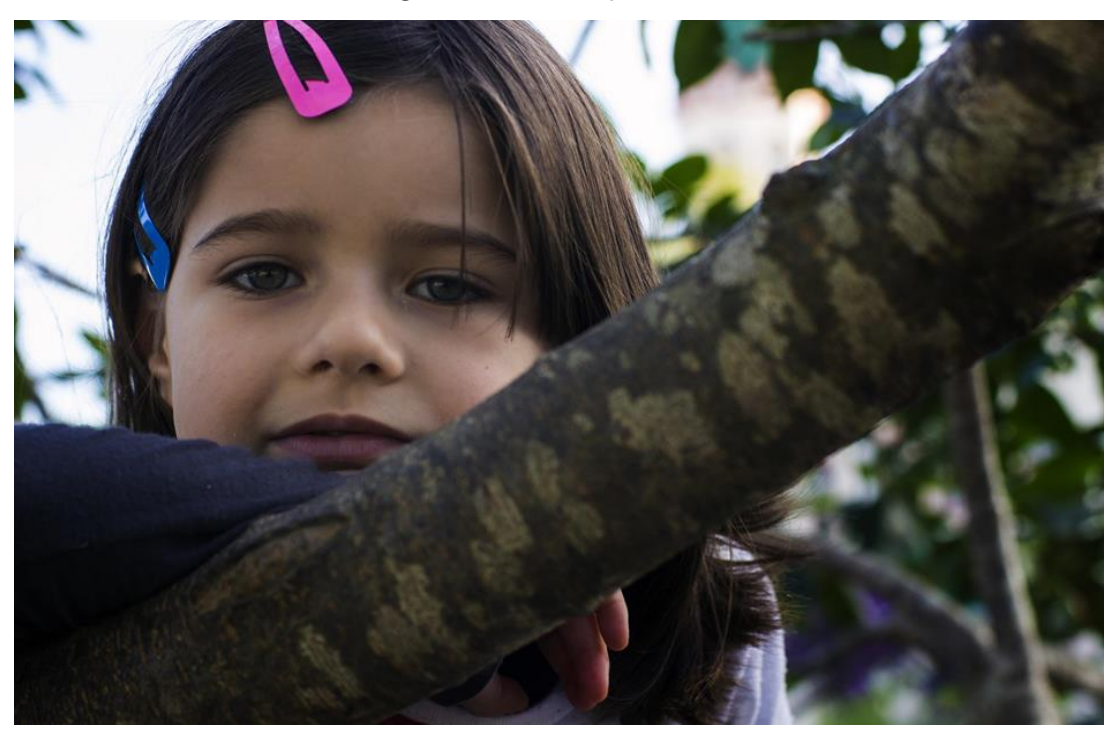

Fonte: Fotografia Rachel Munhoz. 


\section{Olhos de encontro}

Pintei de verde a grama em dia claro

De verde forte e falso e vivo e raro (V. Ramil)

É uma questão particular, mas, dificilmente, uma foto em que a pessoa é o centro da imagem fica ruim quando ela está olhando diretamente para a lente da câmera. Os olhos da menina, acima dos galhos de uma árvore, são emblemáticos ao ponto de não nos deixar claro a sua sensação naquele momento. A mão no queixo mostra alguém que observava a fotógrafa com calma, sem receio do registro, sem timidez ou ansiedade - esta última bastante comum nas crianças quando notam a presença de uma câmera. Porém, ela apenas me assiste enquanto eu a assisto também, mas no meu caso, os olhos estão protegidos pelo equipamento. Assim, ela não olha diretamente para mim, mas sim para o que eu estou fazendo, para o meu ato fotográfico. Deste ponto de vista, imaginei uma inscrição de tempo. Se nós duas estivéssemos próximas, talvez, eu me visse no reflexo dos seus olhos. Não eu, a fotógrafa que ela vê, tornando, assim, a foto, um acionamento da própria fotografia. Ou para quem preferisse remontar esta quarta parede caída, e procurar seu próprio reflexo nos olhos da garota, o que sentiria ao ver a imagem? Minha proposição é a de um encontro. A conjunção que possibilita um tipo diferente de intercâmbio, neste ponto, não somente aprendo sobre minha interlocutora, mas sobre mim também. Inflexão inexistente na solidão que é posta como parte do processo da intelectualidade.

Foto 5: CEI Prof ${ }^{a}$ Juliana de Carvalho Vieira, jun/2018, Joinville-SC

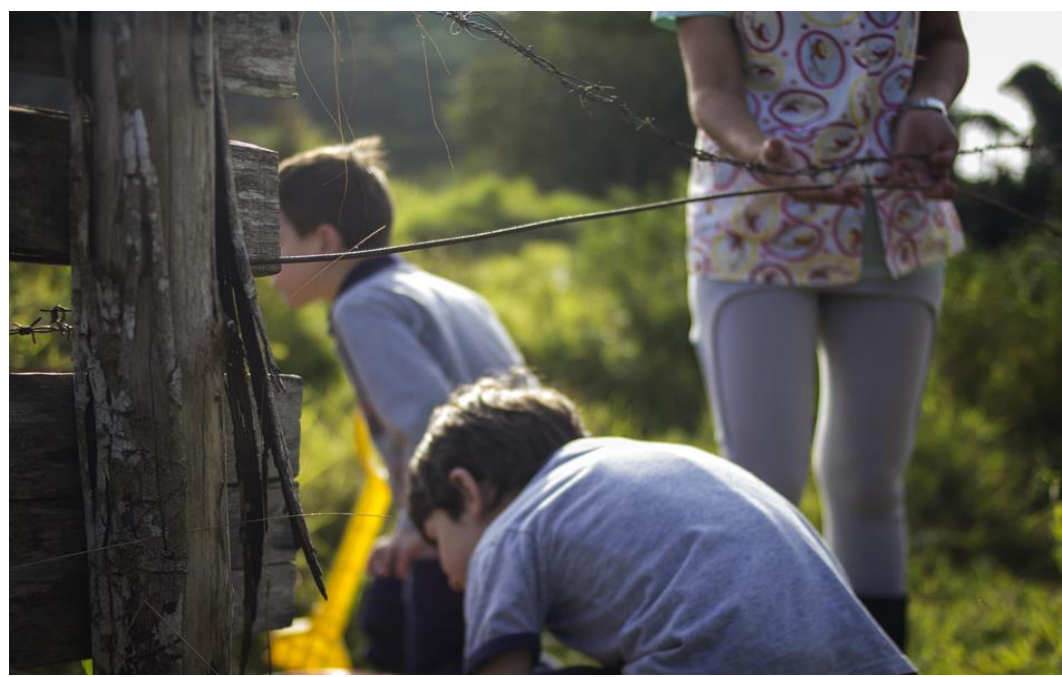

Fonte: Fotografia Rachel Munhoz. 


\section{Tomando o corpo}

Pela grama verde eu quero te ver passar

Pela grama verde eu quero te ver passar

(V. Ramil)

A ementa do projeto em voga trata-se, como vimos, de ressignificar os espaços escolares e, com esta foto, fiz uma tentativa de reproduzir esta mensagem, na medida em que ganhava também mais compreensão do que estava se passando dentro, na verdade, fora, dos CEl's. E, incutido, levo em conta que não apenas de espaços pré-determinados e os brinquedos elaborados dentro da proposta sustentável se fazem tal empresa, mas de criatividade e iniciativa de educadores/as que preferem não fazer, apenas, aquilo que está no projeto. Na imagem, vemos uma adulta erguendo os arames que circundam uma propriedade particular, localizada ao lado do terreno de um CEI menor que a maioria. Trata-se de um acordo feito entre a instituição e os/as proprietários/as do local. Com isso, os/as estudantes se lançam fora do espaço delimitado para o seu aprendizado, expandindo suas possibilidades, todas aquelas que povoarem o imaginário infantil. A opção de não mostrar o rosto da educadora, que dá passagem às crianças com um movimento das mãos, está longe de ter alguma associação com o famoso fenômeno recorrente em desenhos infantis, em que adulto/as aparecem apenas da cintura para baixo e referenciam à questão de autoridade. Neste caso, o anonimato tem intenção de ampliar a identificação com a educadora, no sentido de que outras pessoas podem desempenhar este mesmo papel na educação escolar, desfazendo as linhas impeditivas que ainda, por ora, mentalizamos.

\section{Revelações}

Há algum tempo, seria usual o termo "revelar" para se referir à produção de uma fotografia após o ato do registro. Passaram-se os anos, as tecnologias renovaram os processos de revelação, tornando-os digitais à medida que basta conectar um cabo ao computador para encontrar o que foi fotografado agora em exposição em uma tela.

O surpreendente está não no avanço tecnológico, mas na incapacidade de mudar um elemento sensível: a surpresa. $O$ ato de revelar se mantém e o uso desse verbo ainda é válido pelo simples fato de, ao projetar uma fotografia 
pela primeira vez, trazer à tona o sentimento surpreendente dos arranjos de uma escolha pretérita que se renova, e que passa a ganhar novos sentidos a cada reencontro com o olhar do fotógrafo. Ele, então, rearranja, insere esse evento em outra temporalidade, agora presente, agora capaz de reconstruir mesmo uma relação que pode ocupar-se de outros sentidos, de construção de afetos e saberes que podem ser partilhados.

$O$ ato fotográfico pensado dentro da $E A$, então, vem a ser um núcleo de sentido potente para as relações humanas, compreendendo uma "perspectiva holística, enfocando a relação entre o ser humano, a natureza e o universo de forma interdisciplinar" (TRATADO DE EDUCAÇÃO AMBIENTAL PARA SOCIEDADES SUSTENTÁVEIS E RESPONSABILIDADE GLOBAL, 1992). Daí a responsabilidade de quem fotografa, neste campo, perceber quais mensagens, no que diz respeito à sustentabilidade, acabam inerentes ao processo de fotografar com os olhos já, inconscientemente, direcionados.

Ao folhearmos o diário de campo aqui apresentado, foi possível notar as transformações de um olhar fotográfico, na medida em que a fotógrafa foi submergindo cada vez mais sob o projeto da rede municipal de Joinville e emergindo daquilo que estaria condicionada a ver e captar sobre um tema em específico. Ao descolar-se daquilo que esperava encontrar, além daquilo que fora solicitado de seu trabalho, deixou-se contaminar, buscando ressalvas em seu campo de estudos, os Fundamentos da Educação Ambiental.

Após esta experiência, e os diálogos aqui abertos, esperamos levar adiante o debate já iniciado por outros pesquisadores sobre o uso da fotografia como um dispositivo para intervenções socioambientais, levando em conta a sua contribuição, efetiva, para o campo da EA no favorecimento de um modelo civilizatório baseado na sustentabilidade.

\section{Referências}

CARVALHO, Isabel Cristina de Moura. Educação Ambiental: a formação do sujeito ecológico. 4ª ed. São Paulo: Cortez, 2008.

CHAVEIRO, Eguimar Felício.Corporeidade e Lugar: Elos da produção da existência. In: MARANDOLA JR, Eduardo; HOLZER, Werter; OLIVEIRA, Lívia de. Qual o espaço do lugar? Geografia, epistemologia, fenomenologia. São Paulo: Perspectiva, 2012. 
CRESWEL, John. Projeto de pesquisa: método qualitativo, quantitativo e misto. 2. ed. Porto Alegre: Artmed, 2007.

DUBOIS, Philippe. O Ato fotográfico. $12^{\mathrm{a}}$ ed. Campinas, Papirus, 1993.

GUIMARÃES, Leandro Belinaso; PREVE, Ana Maria. Fotografias de deslocamentos no Ambiente: fugas em uma prática educativa. In: Ciências Humanas e Sociedade em Revista. Rio de Janeiro, EDUR, Vol. 35, n. 2, jul/dez, 2013. p. 48-59.

GUIMARÃES. Leandro Belinaso. A (in)Sustentabilidade da imagem. In: ExperimentArt. Belém, Universidade Federal do Pará. Ano 1, n. 1, jul/dez, 2015, p. 26-39.

GUIMARÃES, Leandro Belinaso. et al [orgs.]. Ecologias inventivas: experiências das/nas imagens. Curitiba, CRV, 2015.

LARROSA, Jorge. Notas sobre a experiência e o saber da experiência. In. Revista Brasileira de Educação. N. 19. Jan/Fev/Mar/Abr, 2002. p. 20-28.

LAYRARGUES, Philippe Pomier. A crise ambiental na perspectiva da relação entre ser humano, tecnologia e natureza. In: FERREIRA, A.A.; FREITAS, E. S. [orgs.]. Meio Ambiente em Cena. Belo Horizonte: Editora RHJ, 2013.

MARTINS, Ronei Ximenes. Metodologia de pesquisa: guia prático com ênfase em educação ambiental. Lavras, UFLA, 2015.

REIGOTA, Marcos. O que é Educação Ambiental. São Paulo, Brasiliense, 2001.

TRATADO DE EDUCAÇÃO AMBIENTAL PARA SOCIEDADES SUSTENTÁVEIS E RESPONSABILIDADE GLOBAL, Documento elaborado pelo Fórum Global das Organizações Não Governamentais, na Conferência das Nações Unidas sobre o Meio Ambiente e Desenvolvimento - Rio de Janeiro, 1992.

TRIVIÑOS, Augusto Nibaldo Silva. Introdução à pesquisa em ciências sociais. A pesquisa qualitativa em educação. São Paulo, Atlas, 1987. 